\title{
Article \\ The Crystallization of Active Pharmaceutical Ingredients with Low Melting Points in the Presence of Liquid-Liquid Phase Separation
}

\author{
Wei Han Lin ${ }^{1} \mathbb{D}$, Zai-Qun Yu ${ }^{2, *} \mathbb{D}$, Pui Shan Chow ${ }^{2} \mathbb{D}$ and Reginald Beng Hee Tan ${ }^{1}$ \\ 1 Department of Chemical \& Biomolecular Engineering, National University of Singapore, 10 Kent Ridge \\ Crescent, Singapore 119260, Singapore; e0325752@u.nus.edu (W.H.L.); reginald@nus.edu.sg (R.B.H.T.) \\ 2 Institute of Chemical \& Engineering Sciences Ltd., A*STAR (Agency for Science, Technology and Research), \\ 1 Pesek Road, Jurong Island, Singapore 627833, Singapore; ann_chow@ices.a-star.edu.sg \\ * Correspondence: yu_zaiqun@ices.a-star.edu.sg
}

Citation: Lin, W.H.; Yu, Z.-Q.; Chow, P.S.; Tan, R.B.H. The Crystallization of Active Pharmaceutical Ingredients with Low Melting Points in the Presence of Liquid-Liquid Phase Separation. Crystals 2021, 11, 1326. https://doi.org/10.3390/ cryst11111326

Academic Editor: Brahim Benyahia

Received: 7 October 2021

Accepted: 29 October 2021

Published: 30 October 202

Publisher's Note: MDPI stays neutral with regard to jurisdictional claims in published maps and institutional affiliations.

Copyright: (c) 2021 by the authors. Licensee MDPI, Basel, Switzerland. This article is an open access article distributed under the terms and conditions of the Creative Commons Attribution (CC BY) license (https:/ / creativecommons.org/licenses/by/ $4.0 /)$

\begin{abstract}
Liquid-liquid phase separation (LLPS) during the crystallization of active pharmaceutical ingredients (APIs) often causes agglomeration and other quality issues in crystal products; thus, it should be avoided if possible. However, LLPS in the crystallization of APIs with low melting points cannot be circumvented in some cases due to yield considerations. The crystallization of ibuprofen in an ethanol/water mixture was studied to explore methods to reduce agglomeration in the presence of LLPS. It was found that unseeded crystallization produced agglomerates when LLPS took place. The two liquid phases resulting from LLPS underwent LLPS again when they were cooled separately, indicating the dynamic nature of LLPS. Seeding and seed ageing at a low supersaturation were very effective in mitigating agglomeration. The effects of two widely used surfactants, i.e., Tween 80 and hydroxypropyl methylcellulose (HPMC), on LLPS and crystallization were confirmed preliminarily. More work needs to be conducted to explore their usefulness in LLPS handling. The findings and techniques presented in this study may be applicable to the crystallization of other APIs with low melting points.
\end{abstract}

Keywords: liquid-liquid phase separation; oiling out; crystallization development; phase diagram

\section{Introduction}

Crystallization defines the quality attributes of small-molecule active pharmaceutical ingredients (APIs), including purity, polymorphism, particle size distribution, crystal shape and morphology, etc. These quality attributes must be tightly controlled as they have impacts either on the therapeutic effects of pharmaceutical products or on the process performance in downstream units such as filtration, drying, blending with excipients and tableting. The occurrence of liquid-liquid phase separation (LLPS), or 'oiling out', has complicated the quality control of an increasing number of APIs. Although some APIs 'melt' and turn into oil droplets during dissolution in hot solvents, other APIs can dissolve normally in hot solvents but undergo LLPS during cooling or anti-solvent addition. LLPS is often associated with impeded spontaneous nucleation, excessively long batch times, 'desert rose' morphology and ineffective impurity rejection.

Due to its detrimental effects on the quality attributes of crystals, various strategies have been adopted to avoid LLPS [1], including lowering the starting concentration and impurity levels, solvent switching, seeding and supersaturation control [2,3], and ultrasound application [4,5]. However, many APIs exhibiting LLPS have relatively low melting points, e.g., idebenone $\left(52.0-55.0^{\circ} \mathrm{C}\right)$ [6], pyraclostrobin $\left(63.7-65.2^{\circ} \mathrm{C}\right)$ [7], butylparaben $\left(68.5^{\circ} \mathrm{C}\right)$ [8], ibuprofen $\left(75.0-77.0^{\circ} \mathrm{C}\right)$ [9], and vanillin $\left(81.0-83.0^{\circ} \mathrm{C}\right)$ [10]. The liquid-liquid equilibrium region in their phase diagrams is easily accessible under usual crystallization conditions. As a result, LLPS cannot be circumvented in their crystallization due to yield considerations. 
Several studies have been published on crystallization in the presence of LLPS, focusing on polymorph control [7], morphological modification [8], and solvent inclusion in crystal products [11]. Seeding was employed in these studies to facilitate crystallization. Seeds provide surfaces on which solute molecules can deposit at a relatively low supersaturation [12]. During seed growth, oil droplets serve as a reservoir of solute [13]. At the same time, oil droplets also act as bridging agents for agglomeration, a possible cause of solvent inclusion and incomplete impurity rejection. This paper aims to test the hypothesis that agglomeration that happens in the presence of LLPS can be mitigated by adjusting seed loadings and cooling profiles. Using ibuprofen as the model compound, the effects of seeding and cooling profiles on crystal agglomeration will be investigated during the crystallization of APIs with relatively low melting points. In addition, many studies have demonstrated that surfactants affect nucleation and crystal growth. Their effects on LLPS and subsequent crystallization has not been reported. The effects of two widely used surfactants, Tween 80 and hydroxypropyl methylcellulose (HPMC), on LLPS and the crystallization of ibuprofen will be studied.

This paper is organized as follows: A general phase diagram will be presented in the next section to explain a few features that are relevant to crystallization and LLPS. Following it is a description of the experimental methods and procedures. Then, a kinetic phase diagram of ibuprofen in a water-ethanol mixture (50/50 v/v) will be displayed, followed by results and discussions on the effects of seeding, cooling profiles and the use of surfactant. The conclusions will be made in the last section.

\section{A Generalized Phase Diagram with LLPS}

A generalized phase diagram is shown in Figure 1 for a binary system that has an upper critical solution temperature, $\mathrm{T}_{\mathrm{UCS}}$.

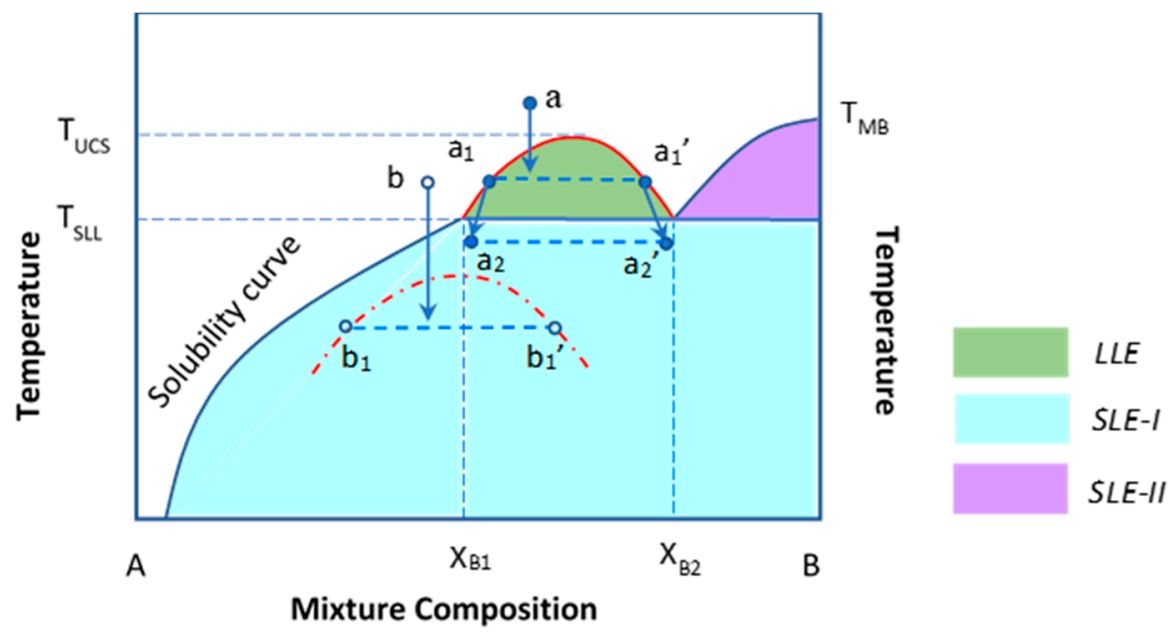

Figure 1. Polythermal diagram of a binary mixture of Components $\mathbf{A}$ (solvent) and $\mathbf{B}$ (solute). The melting point of Component $\mathbf{B}$ is $\mathrm{T}_{\mathrm{MB}}$.

Four equilibrium regions can be identified in the generalized phase diagram, i.e., one liquid region (in white), one liquid-liquid equilibrium region (LLE, in light green) and two solid-liquid equilibrium regions (SLE-I and SLE-II, in sky blue and lavender, respectively). The SLE-I region is bordered on the left by the solubility curve of Component B. Surrounded by a binodal (bold red curve), the LLE region sits on top of the SLE-I region. When the mixture composition falls between $X_{B 1}$ and $X_{B 2}$, one solid phase and two liquid phases can coexist at the temperature $\mathrm{T}_{\mathrm{SLL}}$. For APIs with high melting points, e.g., osanetant $\left(128.0^{\circ} \mathrm{C}\right)$ [14], $\gamma$-aminobutyric acid $\left(203.7^{\circ} \mathrm{C}\right)$ [15] and $\beta$-alanine $\left(207.0^{\circ} \mathrm{C}\right)$ [16], their LLE region is usually not accessible under usual crystallization conditions.

When a solution represented by Point a (filled circle) is cooled into the LLE region, it splits into two stable liquid phases represented by Point $\mathrm{a}_{1}$ and Point $\mathrm{a}_{1}{ }^{\prime}$ on the binodal. 
Point $\mathrm{a}_{1}$ and Point $\mathrm{a}_{1}{ }^{\prime}$ are connected by a bold, dashed tie-line. The composition of the two liquid phases will change continuously along the binodal curve as the dispersion is cooled further. Below $\mathrm{T}_{\mathrm{SLL}}$, their compositions change to Point $\mathrm{a}_{2}$ and Point $\mathrm{a}_{2}{ }^{\prime}$, respectively, and the dispersion becomes meta-stable with respect to the prospective crystal-solution suspension. Further cooling may lead to spontaneous crystal nucleation in one or both liquid phases.

LLPS can also occur below $X_{\mathrm{B} 1}$. When a solution with a composition represented by Point $b$ (empty circle) is cooled below a submerged binodal, it will split into two liquid phases represented by Point $b_{1}$ and Point $b_{1}{ }^{\prime}$ on a submerged binodal [17]. The resulting dispersion is meta-stable with respect to the prospective crystal-solution suspension. Similarly, crystal nucleation may take place in one or both liquid phases if given sufficient time or further cooling.

Many experiments and simulations have been conducted to understand the origin of LLPS. The presence of impurities, solvent-solute interactions and the shape of the potential energy between API molecules all play a part in the occurrence of LLPS [18]. L-sodium glutamate will cause LLPS in the crystallization of $\gamma$-aminobutyric acid when its concentration is greater than $2.0 \mathrm{wt} \%$ [15]. An amphiphilic molecule could crystallize normally in single-component solvents but switching to a water/methanol mixture leads to LLPS [17]. Simulation has revealed that LLPS will occur when the range of molecular attraction is sufficiently smaller than molecule size [19].

\section{Experimental}

Chemicals. Ibuprofen was obtained from the Hubei Biocause Heilen Pharmaceutical Co. Ltd. (Jingmen, China) and it was used as is without further purification. Absolute ethanol (>99.7\%) was purchased from VWR Chemicals. Deionized water was also used.

Measurement procedure for the kinetic phase diagram. Clear points and cloud points of ibuprofen in ethanol/water mixtures were measured by slow heating and slow cooling methods in Crystalline ${ }^{\circledR}$, wherein dissolution and precipitation/LLPS processes can be monitored by transmissivity. Samples were prepared with a known composition of ibuprofen, water, and ethanol. They were heated to a sufficiently high temperature to dissolve all ibuprofen crystals (transmissivity reached 100\%). Then, the samples were cooled slowly at $0.1{ }^{\circ} \mathrm{C} / \mathrm{min}$ until the temperature where the first drop in transmissivity was observed. This was recorded as the cloud point. Then, the samples were heated slowly at $0.1^{\circ} \mathrm{C} / \mathrm{min}$ until the transmissivity reached $100 \%$ and the temperature was recorded as the clear point. Two cycles of cooling-heating were conducted for every sample to obtain an average of two clear points and an average of two cloud points. The decrease in the transmissivity of a clear solution during cooling may be caused by either crystal nucleation or LLPS. The real cause was determined by particle vision measurement (PVM) during subsequent crystallization experiments.

Procedure for crystallization experiments. Crystallization was mainly carried out in a $500 \mathrm{~mL}$ jacketed vessel with a flat bottom, as shown in Figure 2a. The crystallizer was fitted with an overhead stirrer set at $300 \mathrm{rpm}$. The temperature was controlled by a circulating bath (Julabo FP50). The occurrence of LLPS and crystal morphology was monitored using a PVM (model V819 from Mettler Toledo, Columbus, OH, USA).

PVM images. Four representative PVM images are presented in Figure 2. Figure $2 \mathrm{~b}$ is an image of when LLPS took place and it can be seen that the PVM probe window was covered with oil droplets. Figure $2 \mathrm{c}$ was taken when nucleation occurred in the presence of LLPS. Figure $2 \mathrm{c}$ is an image of seeds in the solution without LLPS, and Figure $2 \mathrm{~d}$ is an image of seeds in the presence of LLPS. 


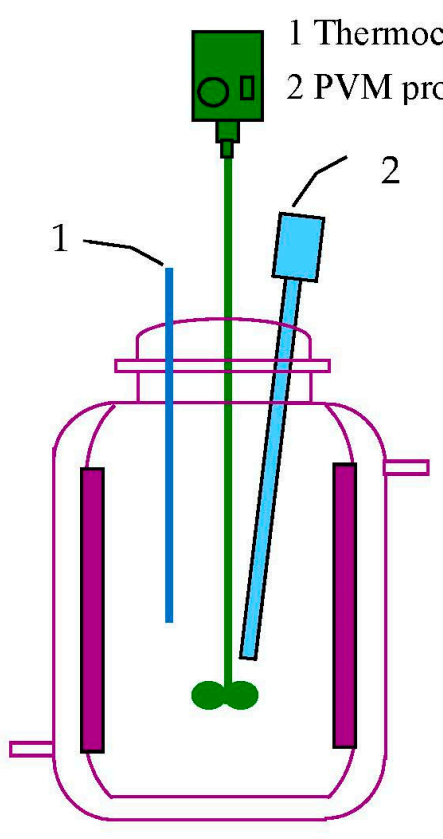

a

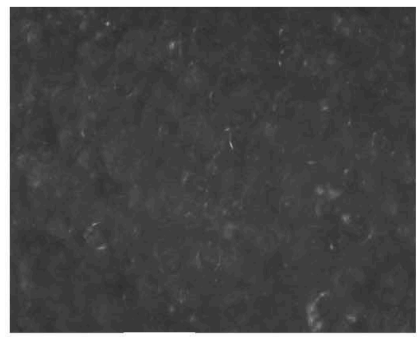

b

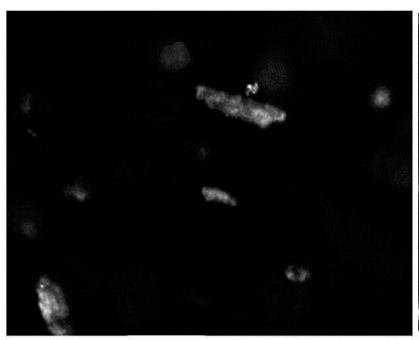

d
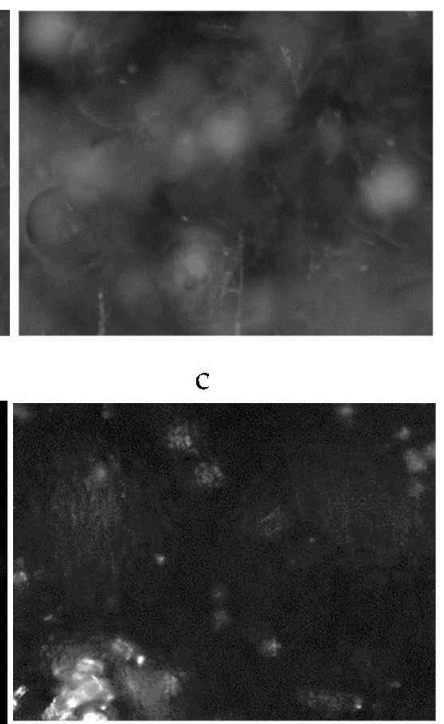

e

Figure 2. (a) Setup for crystallization experiments and representative PVM images; (b) when LLPS took place; (c) when nucleation took place in the presence of LLPS; (d) seeds in the solution without LLPS; (e) seeds in the presence of LLPS.

In the experiments, three different ibuprofen concentrations in an ethanol/water mixture $(50 / 50, v / v)$ were used, including 80,100 and $140 \mathrm{mg} / \mathrm{mL}$ solvents. In each crystallization experiment, the mixture was heated to a temperature $5.0^{\circ} \mathrm{C}$ higher than the corresponding clear point to obtain a clear solution. Then, the solution was cooled at a constant rate to $20.0^{\circ} \mathrm{C}$. After reaching $20.0{ }^{\circ} \mathrm{C}$, the temperature was held constant for $60 \mathrm{~min}$. Combinations of different seed loadings, cooling profiles and additions of surfactant were used to examine their effects on the crystallization process and crystal agglomeration. Crystals were harvested by filtration, followed by drying at room temperature overnight. The size and morphology of the crystals were observed under an optical microscope. Conditions for all crystallization experiments are listed in Table 1 for easy reference.

Table 1. Experimental conditions of crystallization.

\begin{tabular}{cccccc}
\hline Experiment No. & $\begin{array}{c}\mathbf{C}_{\text {start }} \mathbf{m g} / \mathbf{m L} \\
\text { Solvent }\end{array}$ & $\mathbf{T}_{\text {start }},{ }^{\circ} \mathbf{C}$ & $\begin{array}{c}\text { Cooling Rate, } \\
{ }^{\circ} \mathbf{C} / \mathbf{m i n}\end{array}$ & $\mathbf{T}_{\text {seeding, }}{ }^{\circ} \mathbf{C}$ & $\begin{array}{c}\text { Seed Loading, } \\
\mathbf{w t} \%\end{array}$ \\
\hline 1 & 80 & 37.0 & 0.1 & N.A. & 0.0 \\
2 & 100 & 40.0 & 0.1 & N.A. & 0.0 \\
3 & 140 & 45.0 & 0.1 & N.A & 0.0 \\
4 & 80 & 37.0 & 0.1 & 30.0 & 1.0 \\
5 & 100 & 40.0 & 0.1 & 33.0 & 1.0 \\
$7^{*}$ & 140 & 45.0 & 0.1 & 33.0 & 1.0 \\
$8^{*}$ & 140 & 48.0 & 0.1 & 33.0 & 0.0 \\
$9^{*}$ & 140 & 48.0 & 0.1 & N.A. & 0.0 \\
\hline
\end{tabular}

$\mathrm{C}_{\text {start }}$, start concentration of ibuprofen; $\mathrm{T}_{\text {start }}$, starting temperature of cooling profiles; $\mathrm{T}_{\text {seeding, }}$, seeding temperature; ${ }^{*}$, the temperature was held at $33.0^{\circ} \mathrm{C}$ for $75 \mathrm{~min}$ in Experiment 7; \#, surfactant Tween was added in Experiment 8; ${ }^{\wedge}$, surfactant HPMC was added in Experiment 9.

\section{Results and Discussion}

\subsection{Kinetic Phase Diagram}

The kinetic phase diagram of ibuprofen in ethanol/water mixtures $(50 / 50, v / v)$ is shown in Figure 3. 


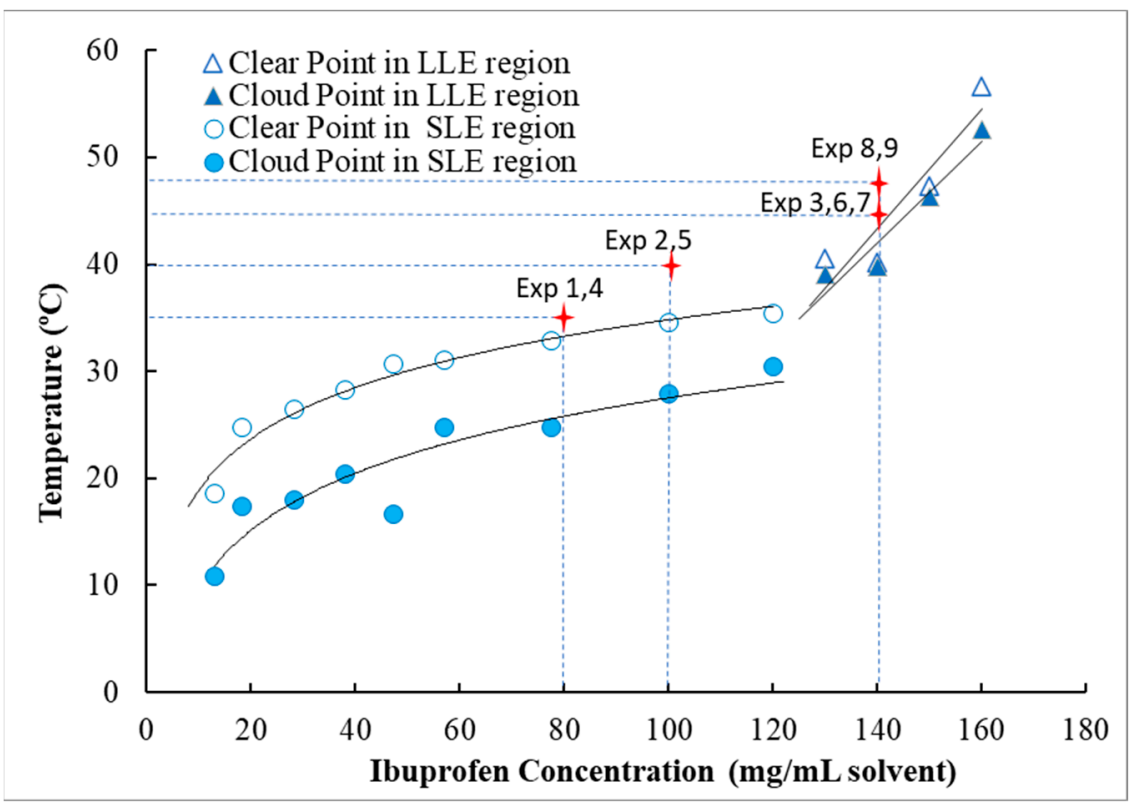

Figure 3. Kinetic phase diagram of ibuprofen in ethanol/water mixtures $(50 / 50, v / v)$. The positions of the starting solution are labelled as bold crosses.

The solid-liquid-liquid equilibrium temperature $\mathrm{T}_{\mathrm{SLL}}$ is around $35.0^{\circ} \mathrm{C}$ with $\mathrm{X}_{\mathrm{B} 1}$ at around $120 \mathrm{mg} / \mathrm{g}$ solvent. A kinetic solubility curve can be obtained by fitting the clear points for ibuprofen concentration $<120 \mathrm{mg} / \mathrm{g}$ solvent. The corresponding cloud points constitute the lower boundary of a meta-stable zone in the SLE region. The maximum ibuprofen concentration measured in this study was $160 \mathrm{mg} / \mathrm{g}$ solvent so only the left part of the LLE region is shown here. The clear points are close to their corresponding cloud points in the LLE region.

The positions of the starting solutions in different experiments are marked as red four-point stars in Figure 3 for easy reference. It can be seen that crystallization with a starting concentration of 80 and $100 \mathrm{mg} / \mathrm{mL}$ solvent will enter the SLE region after cooling, whereas crystallization with a starting concentration of $140 \mathrm{mg} / \mathrm{mL}$ solvent will fall in the LLE region.

\subsection{Effects of Solute Concentration on Crystal Agglomeration in Unseeded Crystallization}

Three unseeded crystallization experiments (Experiments 1, 2 and 3 as indicated in Table 1 and Figure 3) were conducted with a starting concentration of 80, 100 and $140 \mathrm{mg} / \mathrm{g}$ solvent, respectively. The cooling rate for these three experiments was set at $0.1^{\circ} \mathrm{C} / \mathrm{min}$, with starting temperatures of $37.0,40.0$ and $45.0^{\circ} \mathrm{C}$, respectively, to the same final temperature of $20.0^{\circ} \mathrm{C}$. The three starting temperatures were chosen to ensure that all experiments began from homogeneous solutions.

With a starting concentration of $80 \mathrm{mg} / \mathrm{g}$ solvent, nucleation was observed at $24.0{ }^{\circ} \mathrm{C}$ without the occurrence of LLPS. When the starting concentration was increased to $100 \mathrm{mg} / \mathrm{g}$ solvent, LLPS was observed at $30.0^{\circ} \mathrm{C}$. Nucleation did not take place during the cooling period but happened during the holding stage at $20.0^{\circ} \mathrm{C}$. With a starting concentration of $140 \mathrm{mg} / \mathrm{g}$ solvent, the solution underwent LLPS at $42.0^{\circ} \mathrm{C}$. Similar to the case of $100 \mathrm{mg} / \mathrm{g}$ solvent, nucleation did not take place until the holding stage at $20.0^{\circ} \mathrm{C}$. It is not known whether nucleation started first in the oil droplets or in the continuous phase. During LLPS, the solute gets enriched in the oil phase at the expense of the other phases through uphill diffusion in spinodal decomposition [20]. The mass transfer is driven by the difference in the chemical potential of solute between two phases. As LLPS proceeds, the two liquid phases get closer in chemical potential and, thus, have a similar driving force for crystal nucleation. 
The microscopic images of crystals obtained from these three experiments are shown in Figure 4. For a starting concentration of $80 \mathrm{mg} / \mathrm{g}$ solvent, unseeded crystallization produced a mixture of individual crystals and agglomerates, as Figure 4a displays. At the same time, higher starting concentrations (100 and $140 \mathrm{mg} / \mathrm{g}$ solvent) yielded agglomerates only. The agglomerates have irregular morphology and the constituent primary particles are thin plates as shown in Figure $4 \mathrm{~d}$.

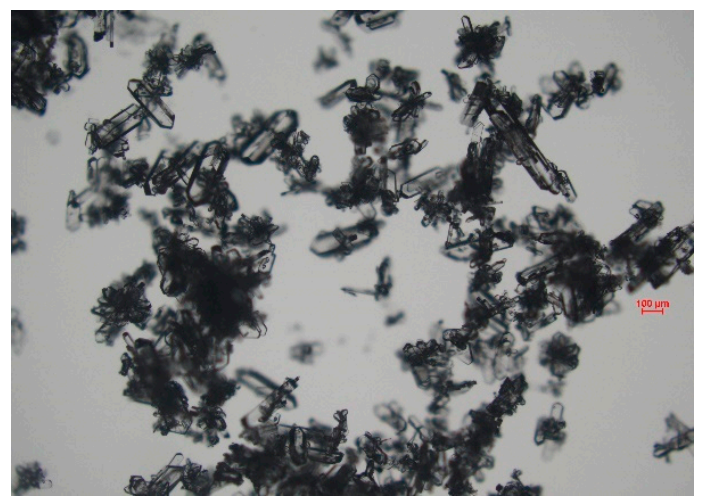

(a)

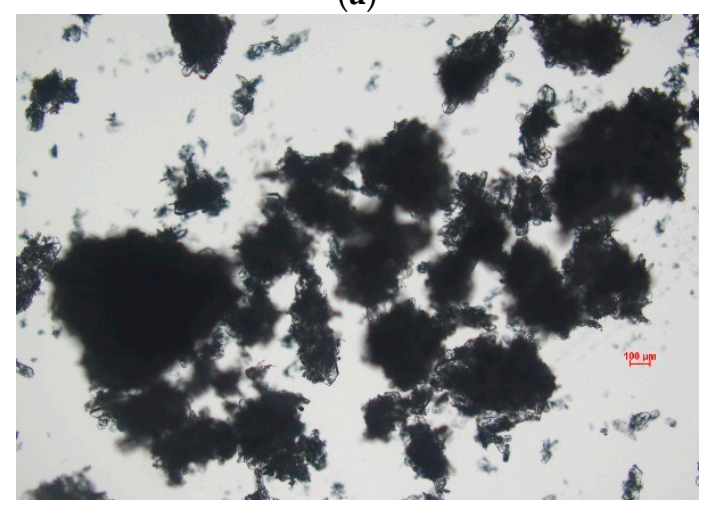

(c)

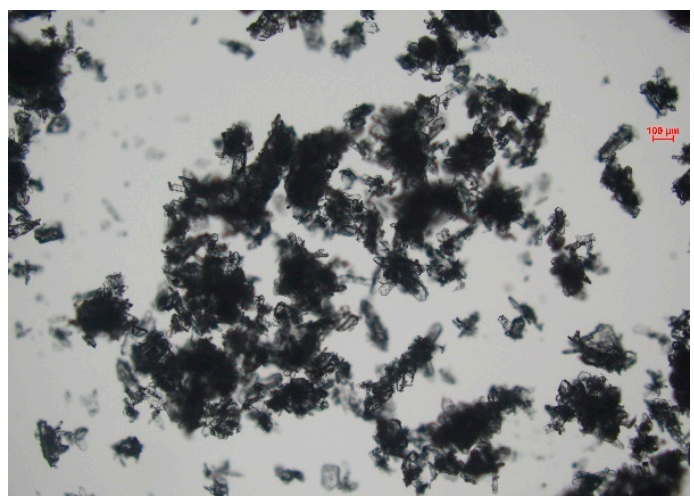

(b)

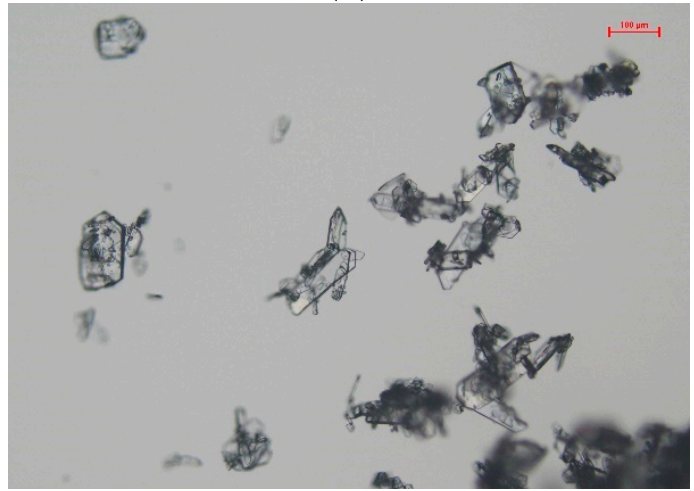

(d)

Figure 4. Microscopic images of ibuprofen crystals harvested from unseeded crystallization with starting concentrations of (a) 80, (b) 100 and (c) $140 \mathrm{mg} / \mathrm{g}$ solvent; (d) microscopic image of the primary particles in agglomerates at higher magnification than the previous three images. The scale bar stands for $100 \mu \mathrm{m}$.

The higher degree of agglomeration in Figure $4 b, c$ can be attributed to the massive nucleation that occurred at a high supersaturation and the occurrence of LLPS. As mentioned earlier, nucleation took place at $20^{\circ} \mathrm{C}$ in these two experiments, whereas the saturation temperature was $40^{\circ} \mathrm{C}$ and $45^{\circ} \mathrm{C}$ in Experiments 2 and 3, respectively. Such a high undercooling induced massive nucleation, producing a lot of small particles that are prone to aggregation. Meanwhile, the high supersaturation promoted crystal growth at the contact points between the primary particles in the aggregates, which would cement the primary particles together.

In quiescent or gently stirred solutions, oil droplets afford a series of separate spherical micro-vessels for crystal nucleation and growth. Nucleation and the subsequent growth therein produce monodispersed spherical agglomerates [14,17]. However, nucleation seemed to take place in both phases in this study, as Figure $2 \mathrm{c}$ indicated, since particles could be found inside and outside oil droplets. In stirred tanks such as the one used in this study, oil droplets possibly serve as bridging agents that promote the agglomeration of small particles [21]. Furthermore, the frequent coalescence and tearing up of droplets due to collisions between one another and with the impeller renders the agglomerate a non-spherical shape. 


\subsection{Secondary LLPS of the Oil Phase and Continuous Phase under Supercooling}

The two liquid phases in the LLE region have different compositions and densities. They become supersaturated after they are cooled to below $\mathrm{T}_{\mathrm{SLL}}$. Their response to supercooling has not been reported. To examine their behavior, $300 \mathrm{~mL}$ of the ibuprofen solution in the ethanol/water mixture $(50 / 50, v / v)$ was prepared with a concentration of $140 \mathrm{mg} / \mathrm{g}$ solvent. It was heated to $45.0^{\circ} \mathrm{C}$ for complete dissolution and then slowly cooled to $33.0^{\circ} \mathrm{C}$ under agitation. LLPS occurred at around $42.0^{\circ} \mathrm{C}$. At $33.0^{\circ} \mathrm{C}$, the overhead stirrer was stopped, and the oil droplets were allowed to coalesce, forming two distinct liquid phases. The two phases were collected and stored separately. Around $50 \mathrm{~mL}$ of the top liquid layer (oil phase) was collected, and the remaining $250 \mathrm{~mL}$ was the denser continuous phase.

The clear and cloud points of each liquid phase were measured by the slow heating and cooling of $50 \mathrm{~mL}$ of each phase separately at $0.1^{\circ} \mathrm{C} / \mathrm{min}$. PVM was used to monitor the process. The procedures were repeated, and the average values of the clear point, cloudy point and nucleation point were obtained. The results are tabulated in Table 2.

Table 2. The behavior of two liquid phases under supercooling.

\begin{tabular}{ccc}
\hline Temperature, $^{\circ} \mathbf{C}$ & Oil Phase & Continuous Phase \\
\hline Clear point & 38.8 & 36.9 \\
Cloud point & 37.7 & 36.2 \\
Nucleation point & 26.2 & 26.9 \\
\hline
\end{tabular}

The oil phase and the continuous phase became homogeneous at 38.8 and $36.9^{\circ} \mathrm{C}$, respectively. When they were cooled, LLPS was observed at $37.7^{\circ} \mathrm{C}$ in the oil phase and at $36.2^{\circ} \mathrm{C}$ in the continuous phase, which was very close to their respective clear points. LLPS results from the minimization of the Gibbs free energy via uphill diffusion. When the primary oil phase is dispersed in the continuous phase as the droplets did in Experiment 3, the Gibbs free energy can be minimized via mass transfer across the large interfaces, with the effect that oil droplets become more concentrated in solute whereas the continuous phase becomes leaner, with each phase remaining homogeneous.

In unseeded crystallization with a starting ibuprofen concentration of $140 \mathrm{mg} / \mathrm{g}$ solvent (Experiment 3), nucleation did not take place after LLPS during the cooling stage. However, when the oil phase and continuous phase were cooled separately, nucleation happened at $26.2{ }^{\circ} \mathrm{C}$ in the former and at $26.9^{\circ} \mathrm{C}$ in the latter. Delayed nucleation in Experiment 3 may be related to the continued mass transfer between the oil phase and the continuous phase, which lowered the chemical potential of solute and, thus, the driving force for crystal nucleation in Experiment 3.

\subsection{Effects of Seeding and Cooling Profiles on Agglomeration}

To mitigate agglomeration, $1 \mathrm{wt} \%$ seeds were added to each of the next four crystallization experiments (Experiments 4-7). Operating parameters for the four experiments can be found in Table 1 and Figure 5. The starting concentration in these four experiments was $80,100,140$, and $140 \mathrm{mg} / \mathrm{g}$ solvent, respectively. The cooling rate was set at $0.1^{\circ} \mathrm{C} / \mathrm{min}$ in all experiments, with the initial temperature at $37.0,40.0,45.0$, and $45.0^{\circ} \mathrm{C}$, and the seeding temperature at $30.0,33.0,33.0$, and $33.0^{\circ} \mathrm{C}$, respectively. The solutions were slightly supersaturated when seeds were added so they did not dissolve. In Experiments 4 and 5, seeds were added before spontaneous nucleation or LLPS. In Experiments 6 and 7, seeds were added after LLPS took place. 


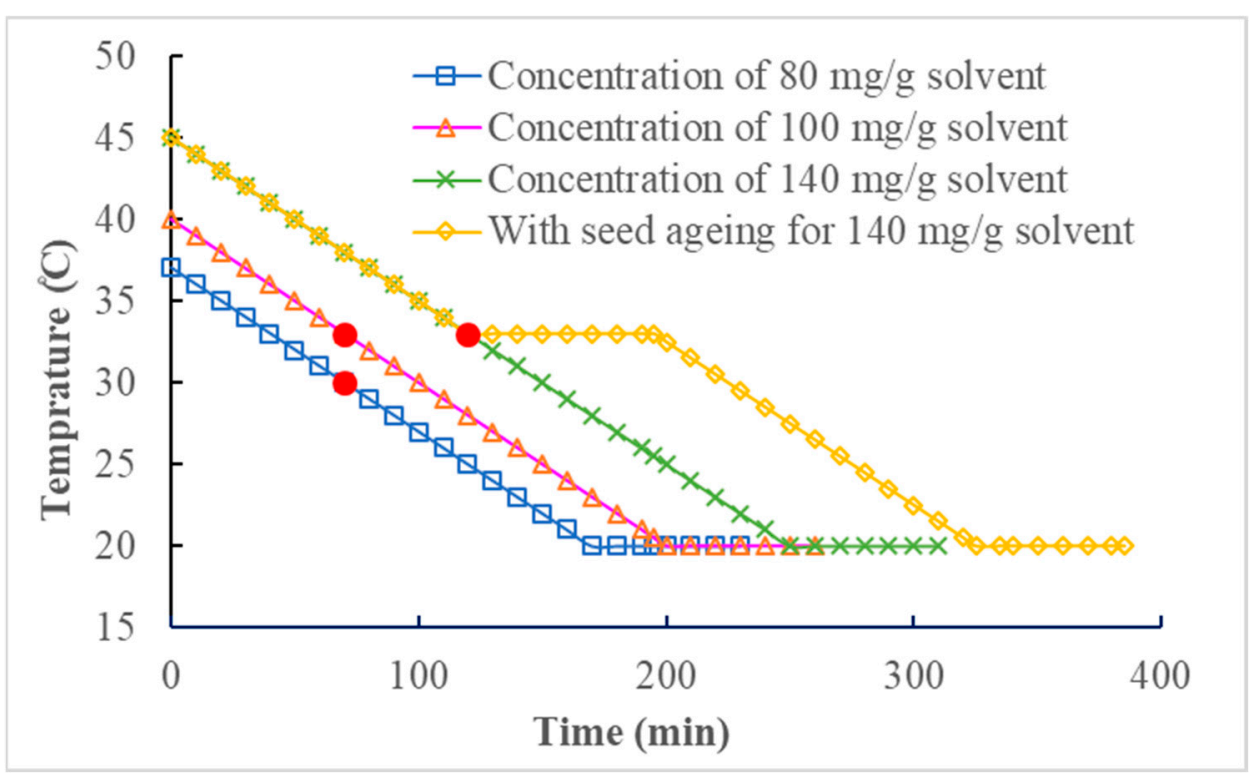

Figure 5. Cooling profiles for seeded crystallization experiments with different starting ibuprofen concentrations (Experiments 4-7). Cooling rate set at $0.1^{\circ} \mathrm{C} / \mathrm{min}$. Seeding points were marked by filled red circles. The two red circles for Experiments 6 and 7 overlapped.

In Experiments 4 to 6, the solution was constantly cooled from the initial temperature to $20.0{ }^{\circ} \mathrm{C}$. In Experiment 7, the dispersion was held at $33.0{ }^{\circ} \mathrm{C}$ for $75 \mathrm{~min}$ after seed application, and then cooling was resumed. PVM showed that after the holding period, the oil droplets disappeared.

The images of the crystals harvested from the four experiments are shown in Figure 6. With starting concentrations of 80 and $100 \mathrm{mg} / \mathrm{g}$ solvent, seeded crystallization produced neat crystals of uniform size with little agglomeration. Seeds provide active surfaces on which solute molecules can deposit at a relatively low supersaturation. For these two starting concentrations, the seed loading of $1 \mathrm{wt} \%$ seemed sufficient at the cooling rate of $0.1^{\circ} \mathrm{C} / \mathrm{min}$ to avoid supersaturation build-up, which suppressed secondary nucleation and LLPS. PVM confirmed that LLPS did not take place at all for the starting concentration of $100 \mathrm{mg} / \mathrm{g}$ solvent.

For the starting concentration of $140 \mathrm{mg} / \mathrm{g}$ solvent, constant cooling still produced agglomerates and a sizeable fraction of small particles, as Figure $6 \mathrm{c}$ shows. The primary particles in these agglomerates are much bigger and thicker than those in Figure 4c. The primary particles of agglomerates are arranged in a radiating manner from a common core. The PVM image in Figure 2e revealed that seeds tend to be attracted by oil droplets, suggesting a possible mechanism as follows: Seeds were dispersed into small clusters around oil droplets. Each seed grew separately by consuming solute molecules inside and outside the host droplet. However, there were not sufficient seed surfaces for solute molecules to deposit on at a rate that matched the generation rate of the supersaturation in the early stage of cooling. Thus, the built-up supersaturation led to the secondary nucleation and agglomeration of growing seeds.

In addition, the mass transfer from the continuous phase to the oil phase (uphill diffusion) might still go on with continued cooling, i.e., the oil droplets became replete with solute molecules over time. In this way, the oil droplets lasted for a lengthened period of time, allowing the agglomeration of growing seeds around them. 


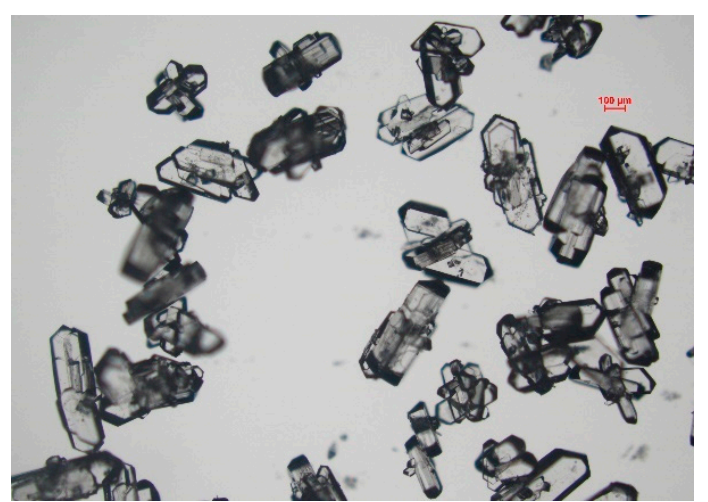

(a)

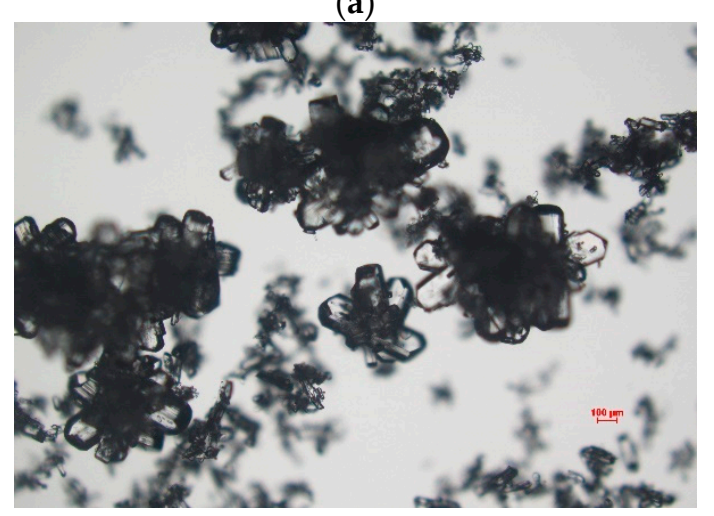

(c)

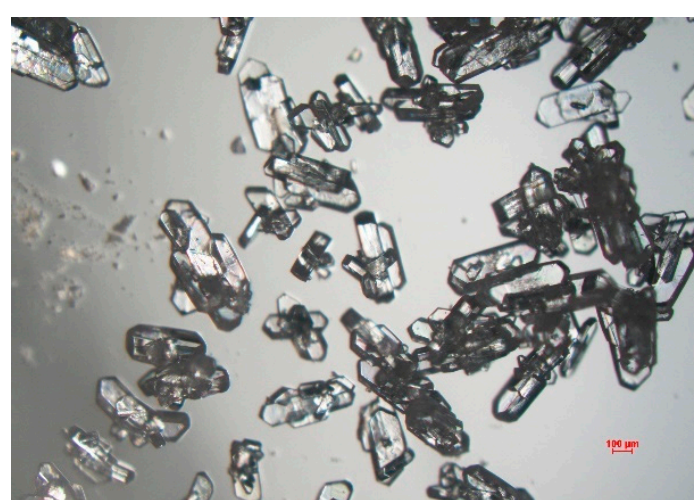

(b)

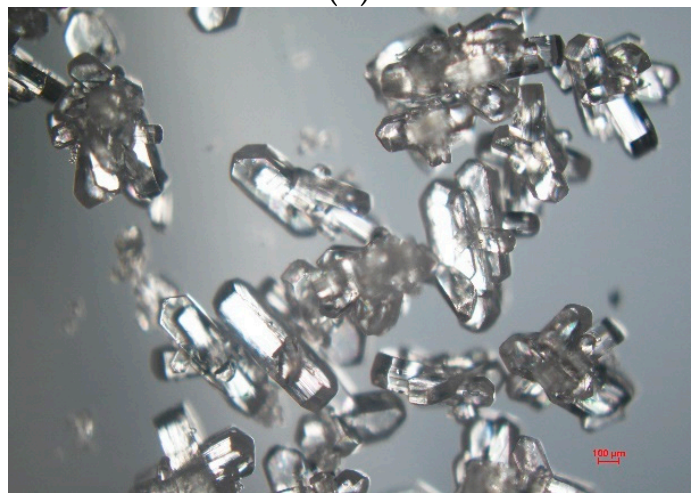

(d)

Figure 6. Effects of the starting concentration and temperature profile on agglomeration with a cooling rate of $0.1^{\circ} \mathrm{C} / \mathrm{min}$ and $1 \mathrm{wt} \%$ seed loading; (a) $80 \mathrm{mg} / \mathrm{g}$ solvent and constant cooling; (b) $100 \mathrm{mg} / \mathrm{g}$ solvent and constant cooling; (c) $140 \mathrm{mg} / \mathrm{g}$ solvent and without seed ageing; (d) $140 \mathrm{mg} / \mathrm{g}$ solvent with seed ageing.

With a temperature holding stage in the cooling profile of Experiment 7, the agglomeration and the fraction of small particles were reduced greatly (Figure $6 \mathrm{~d}$ ). The holding stage gave seeds sufficient time to consume solute molecules in both phases at a low supersaturation. The supersaturation can be estimated from the kinetic phase diagram (Figure 3). The solid-liquid-liquid equilibrium temperature $\mathrm{T}_{\mathrm{SLL}}$ was around $35.0^{\circ} \mathrm{C}$. At the seeding temperature of $33.0^{\circ} \mathrm{C}$, the supersaturation measured in the temperature difference can be estimated as $2.0^{\circ} \mathrm{C}$. At this supersaturation, crystal growth was sustained without nucleation being induced.

\subsection{Use of Surfactant}

Surfactants can change the surface tension of oil droplets and affect LLPS. They may also change the size of oil droplets. A dispersion with larger droplets can produce more nuclei than one with smaller droplets [22]. As a preliminary study on the effects of surfactants, Experiments 8 and 9 were conducted with Tween 80 and HPMC added to the starting solutions, respectively. Using Experiment 3 as a control, the starting concentration was set at $140 \mathrm{mg} / \mathrm{g}$ solvent in Experiments 8 and 9. The concentration of surfactants was $0.5 \mathrm{wt} \%$ of the solvent. The mixture was heated to $48^{\circ} \mathrm{C}$ to obtain a clear solution. Then it was cooled at $0.1{ }^{\circ} \mathrm{C} / \mathrm{min}$ to $20.0^{\circ} \mathrm{C}$, followed by a holding stage at $20.0^{\circ} \mathrm{C}$ for $60 \mathrm{~min}$.

Remember that LLPS occurred at $42.0^{\circ} \mathrm{C}$ and nucleation happened during the temperature holding stage at $20.0^{\circ} \mathrm{C}$ without surfactant (Experiment 3). With Tween 80, the mixture turned completely cloudy at $44.5^{\circ} \mathrm{C}$. However, no nucleation was observed at the end of the experiment. With HPMC, the mixture turned cloudy once the HPMC was added at $48.0^{\circ} \mathrm{C}$. Nucleation was observed during the temperature holding stage at $20^{\circ} \mathrm{C}$ and the crystal image is shown in Figure 7. Compared with Figure 4c, the particles obtained with the addition of HPMC were less agglomerated and had bigger primary crystals. 


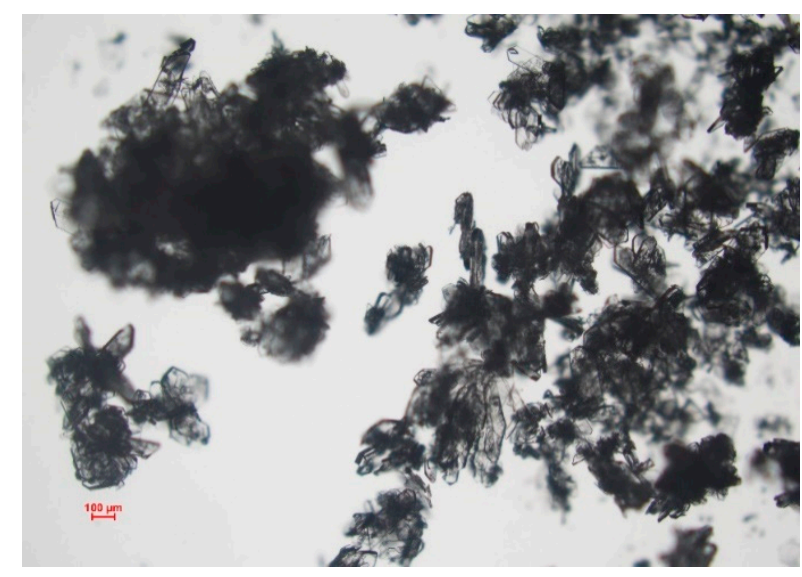

Figure 7. Crystals obtained in the unseeded crystallization with HPMC.

Although the cloud point is affected by the use of surfactants as this study shows, more research is needed to understand how surfactants influence the dynamics of LLPS and, in turn, nucleation and crystal growth. This knowledge can then be employed when addressing the issue of LLPS in pharmaceutical crystallization.

\section{Conclusions}

The liquid-liquid phase separation (LLPS) and crystallization behavior of ibuprofen in an ethanol/water mixture has been studied. The occurrence of LLPS depended on the starting concentration. In the presence of LLPS, crystallization produced highly agglomerated crystals. LLPS that occurred under the solubility curve in the polythermal phase diagram could be circumvented by seeding. Meanwhile, the LLPS originating in the liquid-liquid equilibrium region could not be avoided. The agglomeration of crystals could be mitigated by seeding. Moreover, seed ageing at a low supersaturation was very effective at reducing agglomeration in the presence of LLPS. The oil phase and continuous phase resulting from LLPS underwent LLPS again when they were cooled separately. Nucleation seemed to be enhanced by the separate cooling of these two phases. The use of surfactants led to changes in LLPS and crystallization. More systematic work needs to be done for a mechanistic understanding of surfactant effects. The findings and techniques in this study may be applicable to the crystallization of other APIs with relatively low melting points.

Author Contributions: Conceptualization, R.B.H.T. and Z.-Q.Y.; methodology and experimentation, W.H.L. and Z.-Q.Y.; writing — original draft preparation, W.H.L.; writing—review and editing, Z.-Q.Y. and P.S.C. All authors have read and agreed to the published version of the manuscript.

Funding: This research received no external funding.

Institutional Review Board Statement: Not applicable.

Informed Consent Statement: Not applicable.

Data Availability Statement: All data, models, or codes that support the findings of this study are available from the corresponding authors upon reasonable request.

Acknowledgments: In this section, you can acknowledge any support given which is not covered by the author contribution or funding sections. This may include administrative and technical support, or donations in kind (e.g., materials used for experiments).

Conflicts of Interest: The authors declare no conflict of interest. 


\section{References}

1. Yu, Z.-Q.; Zhang, F.-K.; Tan, R.B.H. Liquid-liquid phase separation in pharmaceutical crystallization. Chem. Eng. Res. Des. 2021, 174, 19-29. [CrossRef]

2. Duffy, D.; Cremin, N.; Napier, M.; Robinson, S.; Barrett, M.; Hao, H.; Glennon, B. In situ monitoring, control and optimization of a liquid-liquid phase separation crystallization. Chem. Eng. Sci. 2012, 77, 112-121. [CrossRef]

3. Kim, S.; Wei, C.; Kiang, S. Crystallization Process Development of an Active Pharmaceutical Ingredient and Particle Engineering via the Use of Ultrasonics and Temperature Cycling. Org. Process. Res. Dev. 2003, 7, 997-1001. [CrossRef]

4. Gao, Z.; Altimimi, F.; Gong, J.; Bao, Y.; Wang, J.; Rohani, S. Ultrasonic Irradiation and Seeding To Prevent Metastable Liquid-Liquid Phase Separation and Intensify Crystallization. Cryst. Growth Des. 2018, 18, 2628-2635. [CrossRef]

5. Parimaladevi, P.; Supriya, S.; Srinivasan, K. The role of ultrasound in controlling the liquid-liquid phase separation and nucleation of vanillin polymorphs I and II. J. Cryst. Growth 2018, 484, 21-30. [CrossRef]

6. Lu, J.; Li, Y.-P.; Wang, J.; Li, Z.; Rohani, S.; Ching, C.-B. Study on the Oiling-out and Crystallization for the Purification of Idebenone. Org. Process. Res. Dev. 2012, 16, 442-446. [CrossRef]

7. Li, K.; Wu, S.; Xu, S.; Du, S.; Zhao, K.; Lin, L.; Yang, P.; Yu, B.; Hou, B.; Gong, J. Oiling out and Polymorphism Control of Pyraclostrobin in Cooling Crystallization. Ind. Eng. Chem. Res. 2016, 55, 11631-11637. [CrossRef]

8. Yang, H.; Chen, H.; Rasmuson, Å.C. Sandwich crystals of butyl paraben. CrystEngComm 2014, 16, 8863-8873. [CrossRef]

9. Rashid, A.; White, E.T.; Howes, T.; Litster, J.D.; Marziano, I. Effect of Solvent Composition and Temperature on the Solubility of Ibuprofen in Aqueous Ethanol. J. Chem. Eng. Data 2014, 59, 2699-2703. [CrossRef]

10. Svärd, M.; Gracin, S.; Rasmuson, Å.C. Oiling out or molten hydrate-Liquid-liquid phase separation in the system vanillin-water. J. Pharm. Sci. 2007, 96, 2390-2398. [CrossRef] [PubMed]

11. De Albuquerque, I.; Mazzotti, M. Influence of Liquid-Liquid Phase Separation on the Crystallization of L -Menthol from Water. Chem. Eng. Technol. 2017, 40, 1339-1346. [CrossRef]

12. Zhang, F.; Shan, B.; Wang, Y.; Zhu, Z.; Yu, Z.-Q.; Ma, C.Y. Progress and Opportunities for Utilizing Seeding Techniques in Crystallization Processes. Org. Process. Res. Dev. 2021, 25, 1496-1511. [CrossRef]

13. Tanaka, K.; Takiyama, H. Effect of Oiling-Out during Crystallization on Purification of an Intermediate Compound. Org. Process. Res. Dev. 2019, 23, 2001-2008. [CrossRef]

14. Veesler, S.; Revalor, E.; Bottini, A.O.; Hofft, C. Crystallization in the Presence of a Liquid-Liquid Phase Separation. Org. Process. Res. Dev. 2006, 10, 841-845. [CrossRef]

15. Sun, M.; Du, S.; Yang, J.; Wang, L.; Gao, Z.; Gong, J. Understanding the Effects of Upstream Impurities on the Oiling-Out and Crystallization of $\gamma$-Aminobutyric Acid. Org. Process. Res. Dev. 2020, 24, 398-404. [CrossRef]

16. Sun, M.; Du, S.; Chen, M.; Rohani, S.; Zhang, H.; Liu, Y.; Sun, P.; Wang, Y.; Shi, P.; Xu, S.; et al. Oiling-Out Investigation and Morphology Control of $\beta$-Alanine Based on Ternary Phase Diagrams. Cryst. Growth Des. 2018, 18, 818-826. [CrossRef]

17. Bonnett, P.E.; Carpenter, K.J.; Dawson, S.; Davey, R.J. Solution crystallisation via a submerged liquid-liquid phase boundary: Oiling out. Chem. Commun. 2003, 2003, 698-699. [CrossRef] [PubMed]

18. Asherie, N.; Lomakin, A.; Benedek, G.B. Phase Diagram of Colloidal Solutions. Phys. Rev. Lett. 1996, 77, 4832-4835. [CrossRef] [PubMed]

19. Dumetz, A.C.; Chockla, A.M.; Kaler, E.W.; Lenhoff, A.M. Protein Phase Behavior in Aqueous Solutions: Crystallization, LiquidLiquid Phase Separation, Gels, and Aggregates. Biophys. J. 2008, 94, 570-583. [CrossRef]

20. Favvas, E.P.; Mitropoulos, A.C. What is spinodal decomposition\&63. J. Eng. Sci. Technol. Rev. 2008, 1, $25-27$.

21. Wang, L.; Bao, Y.; Sun, Z.; Pinfield, V.J.; Yin, Q.; Yang, H. Investigation of Agglomeration in the Presence of Oiling Out in the Antisolvent Crystallization Process. Ind. Eng. Chem. Res. 2021, 60, 4110-4119. [CrossRef]

22. Takasuga, M.; Ooshima, H. Control of Crystal Size during Oiling Out Crystallization of an API. Cryst. Growth Des. 2014, 14, 6006-6011. [CrossRef] 